\title{
A Study on the Teacher-Student Relationship and its Impact on the Behaviour of High School Students
}

\author{
Gururaj Ganapati Gouda ${ }^{1}$ \& Laveena D’Mello ${ }^{2}$ \\ ${ }^{1}$ Research Scholar, College of Social Science \& Humanities, Srinivas University, Mangalore, \\ Karnataka, India. \\ Email: gururajitgi@gmail.com \\ ${ }^{2}$ Associate Professor, College of Social Science \& Humanities, Srinivas University, \\ Mangalore, Karnataka, India. \\ E-mail: lavynoronha@gmail.com
}

Type of the Paper: Explorative Research.

Type of Review: Peer Reviewed.

Indexed In: OpenAIRE.

DOI: http://doi.org/10.5281/zenodo.2589822.

Google Scholar Citation: IJCSBE

\section{How to Cite this Paper:}

Gouda, Gururaj Ganapati, \& D’Mello, Laveena. (2019). A Study on the Teacher-Student Relationship and its Impact on the Behaviour of High School Students. International Journal of Case Studies in Business, IT, and Education (IJCSBE), 3(1), 28-34.

DOI: http://doi.org/10.5281/zenodo.2589822.

International Journal of Case Studies in Business, IT and Education (IJCSBE)

A Refereed International Journal of Srinivas University, India.

(C) With Authors.

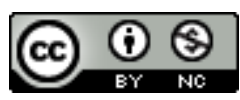

This work is licensed under a Creative Commons Attribution-Non Commercial 4.0 International License subject to proper citation to the publication source of the work.

Disclaimer: The scholarly papers as reviewed and published by the Srinivas Publications (S.P.), India are the views and opinions of their respective authors and are not the views or opinions of the S.P. The S.P. disclaims of any harm or loss caused due to the published content to any party. 


\title{
A Study on the Teacher-Student Relationship and its Impact on the Behaviour of High School Students
}

\author{
Gururaj Ganapati Gouda ${ }^{1}$ \& Laveena D’Mello ${ }^{2}$ \\ ${ }^{1}$ Research Scholar, College of Social Science \& Humanities, Srinivas University, Mangalore, \\ Karnataka, India. Email: gururajitgi@gmail.com \\ ${ }^{2}$ Associate Professor, College of Social Science \& Humanities, Srinivas University, \\ Mangalore, Karnataka, India. \\ E-mail: lavynoronha@gmail.com
}

\begin{abstract}
High school students are in the stage of Adolescence and it is the time for developing independence. Typically, adolescents exercise their independence by questioning and sometimes by breaking rules. Parents and teachers must play a major role in supporting \& influencing the children positively by their ethical \& appropriate approaches. Teachers in school as well as parent at home, often wonder how to disciple a child and to mould their behaviour so to bring up the child with virtues. Although some children truly have challenging behaviours regardless of what strategies to try, many children just need to have the adults in their lives make changes in the way they react, respond, or interact with them. It is also a great responsibility of the teacher in school to have positive approach towards students. If not there are possibilities in change of behaviour among students \& leads to several problems. For example, frequent episodes of fighting, scholastic backwardness, substance abuse; antisocial or institutional activities, destructive behaviour and change in attitude in students are much more significant than isolated episodes of the same activities. Other warning signs include deterioration of performance at school and running away from home. This research paper's aim is the teacher-students relationship and its impact on the behaviour of High school students. The objectives are to know the teachers attitudes both positive and negative towards students and its impact to bring positive as well as negative behaviour change in the students. The study has reported that students are often facing emotional problems by the negative approach of the teachers. It is recommended that to create awareness among teachers in the school for the smooth handling the children with the positive approaches. 50 high school students; 25 girls and 25 boys were taken and interview schedule is used. Both the primary and secondary methods are used and the study is descriptive in nature.
\end{abstract}

Keywords: Students, Teachers, Behaviour, Adolescents, School and Relationship.

\section{INTRODUCTION :}

To find out the behavioural changes in students by the approach of teachers in the classroom, it is necessary to understand the several behavioural problems experienced by students and deferent approaches done by teachers. Normally in Indian schools the teachers follow some traditional \& unethical approaches to influence the students towards academic or activities [1]. These approaches will negatively influence the chid to get discouraged, misbehaved and also it will impact on the performance of the child in the academic or activities [2]. This is a main cause behind individual's behaviour in the society. The time students complete their education and come to the social life, the impact of the negative approach in the school by the teacher will be exhibited through its personality [3-4]. By this negative and inappropriate behaviour will spoil the respect, identity and social acceptance of the individual. So it is very essential to change the approach in the school which brings appropriate behaviour and social acceptance to the child in the society [5]. 


\section{OBJECTIVES OF THE STUDY :}

The relationship between teachers and students is one of the important tools used in shaping the students personality. To know the status of the relationship and its effect on students behaviour in the classroom learning process, the following objectives are been discussed.

(1) To identify the behavioural problems of the high school students

(2) To understand the status of relationship between teachers and students

(3) To find the causes behind the student's behavioural problems

(4) To explore the impact of the relationship between teachers and students on students' academic performance

(5) To find out the deferent approaches of the teachers on student's misbehaviour

\section{APPROACHES AT THE SCHOOL :}

Physical abuse: Two out of three school going children in India are physically abused says the national report on child abuse by the Ministry of Women and Child Development in 2007 [6]. The crime is increasingly noticed in every single district of the country [7].In India boys are marginally more likely to face physical abuse (73 per cent) than girls (65 per cent). Corporal punishment in both government as well as private educational institutions is deeply ingrained as a tool to discipline children and as a normal action [8-10]. But most children do not report or confide about the problem to anyone and suffer silently. To help and encourage children with several emotional and a behavioural problem a set of approach is formed. The positive and healthy parenting and classroom management by the teacher model is based on the great work done by the Alfred Adler and Rudolf Dreikurs which started in the year of 1920s. It consists of a specific set of techniques for inculcating positive behaviour and curtailing negative behaviours. It is a well-known approach designed to teach children to become responsible, respectful and resourceful and inculcates a spirit of self-discipline [11].

Social influence: Due to the change in the life style, work stress, family related issues individual do not have a healthy communication, He frequently fall in to imbalance in his emotions and thoughts [12]. These are the major facts to decide the individuals approach towards others. The researchers say that in India majority of the schools reported that they consider corporal punishment as better way to correct the child in its behaviour. Even though corporal punishment has been classified as an act of violence and abuse on children, until today in India children are abused physically and mentally in the schools [13-14]. Corporal punishment is one of the major approaches by the teacher such as beating, pinching, hitting the child with tools like belts, hands, sticks etc. Such type of violence may be a deliberate act of punishment or simply the impulsive reaction of the an irritated teacher, no matter what form the violence however it will have an negative impact in the child's behaviour. This should be considered seriously so that corporal punishment is banned in every school [15-16].

Mental abuse: Not only physical abuse, even mental abuse of the child in the school is one of the causes behind inappropriate behaviour of the child [17]. One of the challenging problems in developing India is that suicidal thoughts in children. High expectation by the teacher in their academic, creating unhealthy computation between low and high academic performance, study pressure, non-availability of a conducive environment in schools by the teachers for the child to share feelings can also influencing the Child's mental state [18], [10]. Any type of abuses of the child (physical, mental, emotional) is against the child rights and punishable. But also repetitive irritation by the child in the classroom or inability of the child to cope with the teacher's expectation is making the teachers fall in taking action against child by abusing them physically or mentally. Such as scolding, threaten to complaint the parents and principal, issue the transfer certificate, insulting the child in class, scolding the parents, not giving importance to the child, indirectly taunting at them and being partial to the particular child. These types of mental abuse is also will damage the behaviour of the child to develop several unhealthy attitude and suicidal thoughts [19-20].

\section{BEHAVIOUR CHANGE AND PROBLEMS IN CHILDREN :}

Beyond violating a fundamental right of the child causes pain, injury, and humiliation, anxiety and anger in child's behaviour that could have long term psychological effect and destroy the personality 
of the child [13]. Repeated negative approach by the teacher in the school may exhibit dysfunction behaviour such as poor communication and child may report aggressive behaviour towards itself and others [21]. These are the unethical approaches of the teacher may a significant reason for child to dropping out of school. Emotionally or physically effected children by the negative approach of the teachers may also refuse to return and think against the teachers and subject [22-23].

Deferent problems among children: Child abuse in the school can produce feelings of guilt, violation, loss of self-control and degraded self-esteem [14]. It may influence the child in to the feeling of hopelessness, worthlessness and uselessness which will leads suicidal thoughts [11]. Physical and mental abuse of the children in the schools may reinforce them in to revenge and identity of failure. The children interviewed also reported that, when they experience negative approach of the teacher they feel hurt exhibit their pain through anti-social thinking or activity [24]. Negative approach by the teachers in the school towards children is totally against to the law. Violation in child right leads to permanent damage in the child's behaviour. In India many schools are considering some unethical \& traditional approaches are as recognized law; though it leads to negative behaviour among children the teachers in schools tend to have these negative approaches repetitively [25].

\section{RELATIONSHIP BETWEEN APPROACH AND BEHAVIOUR :}

Deferent approaches: Approach of the family, peers, society and teachers in the school will play the major role in shaping the behaviour of children [26]. There is a direct relationship between approach of the external world and behaviour of the individual as most of the behavioural corrections done by deferent approaches. Mother use the love and care as an approach to train the child to get adopted the same behaviour towards others [27]. In the other hand teacher use hitting or scolding asan approach to make child get corrected in its mistakes; but during the interview majority of the children have reported that they also use the same approach towards others done by the teachers. If there is a change in the behaviour of the child as negative or positive in the school it is definitely the approach made by teachers, peers or by the family [26].

Behaviour change by approach: There are several reasons behind the teacher's approach towards children. That may be the work pressure given by the management or heads of the organization, emotional disturbance by the family, lack of patience to understand the child its behaviour, sometime lost humanity due to the modern life style may influence the teachers to have an unhealthy approach towards children [28] [12]. The other hand human behaviour is a varied aria of study but in this study the miner part of the child's behaviour in the school is taken such as lying, negative attitude towards teacher and subject, Destructive behaviour, Bullying and isolation by the social involvement[29]. For example: if mathematics teacher scold or hit the child in front of class mates for the reason of scoring the less marks; the child starts developing negative attitude towards that particular subject and teachers. A common behavioural problem in the children is lying; which is also one of the problems caused by approach of the teacher.

Problems of behaviour change: When the child shows the interest to share the mistake committed to the teachers, if teacher encourage and give them an opportunity to tell their problem they feel to tell the truth if not they lie. Sometime fear on teacher also will influence the child to develop lying behaviour [29]. During the interview children reported that the time teacher negatively approach the children they get angry and emotionally disturbed; but they are not able to exhibit it in front of teachers. In such time they develop a destructive behaviour by exhibiting such behaviour towards friends in the school and neighbourhood, family members, school properties and things [9], [10]. If the teachers approach is negative and damaging the emotional wellbeing of the child may that make the child falls down to the social isolation [30].

\section{RELATIONSHIP BETWEEN TEACHER AND STUDENT :}

Those students have close, positive and supportive relationship with their teachers will reach the higher level of success in academics, extra-curricular activities as well as in their social life [6]. The students with more conflict in relationship with their teachers will slowdown in their wellbeing at day today's life. A positive relationship builds healthy communication. It may motivate, encourage and bring the students up to the activeness and more involvement in learning, improve positive behaviour 
in both at class and home [22]. A student will spend valuable time in school with teachers then spending at home and it is a time to learn social values, ethics, culture and many more. Teachers play the ultimate role in influencing the students positively to get adapted all the good and appropriate behaviour [6].

Behavioural impact by negative relationship: If there is unhealthy relationship between teacher and student, student may get increased anger, demotivation, discourage, miss behaviour, negative changes in attitude, disrespect towards others may block the active and positive growth of overall personality of the child [9]. It is very essential to the teacher to understand and create healthy, supportive and positive relationship with their students [22]. Important responsibility of the teacher is to create flexible environment that students feel free to share their feelings. Once they start talking, teacher should develop a confidence in students [18]. Teacher should appreciate the student for selecting them as right person to share their feelings by maintaining confidentiality and respecting student's feelings. Teacher should play the major role in guiding, by making them understand about the mistake committed, miss behaved or by telling them about their great responsibilities in the school, home and society [6]. Approach based on empathy will make the students to go beyond the intentions of the guidance, expectation and the responsibility given by both parents and teachers. "In every child's life parents are important, for student's teachers". To have healthy academic experience it is very essential for both teachers and students to understand that the importance and necessity of the mutual understanding and have positive relationship between them [18], [22].

\section{ANALYSIS :}

Personal Data: Number of respondents taken for the study is 50. Male respondents were $50 \%$ and female were $50 \% .40 \%$ of respondents aged between 15 and 16 years, 30\% between 14 and 15 years and $30 \%$ between 13 and 14 years of age. 94\% of samples belong to Hindu religion and $6 \%$ of samples from Muslims. Education vice distribution of the sample is $30 \%$ from the class $8^{\text {th }}, 30 \%$ from class $9^{\text {th }}$ and $40 \%$ samples from class $10^{\text {th }}$.

Behavioural problems in adolescents: The report of the data collected from the samples indicates that $54 \%$ of the male and $38 \%$ of female respondents often fall in to the depression by the academic pressure given by teachers. $68 \%$ of male respondents and $64 \%$ of female respondents developed negative attitude towards subjects and teachers. $18 \%$ respondents expressed that they often fall in to isolation and $48 \%$ of respondents showed aggressive behaviour towards peers. $32 \%$ of respondents are scholastically backwards and $22 \%$ of respondents have hyperactive disorders.

Teacher's approach towards students: The approach related problems experienced by the respondents were identified for $72 \%$ of scolding by the teacher, 34\% physical abuse and 38\% mental abuse. $64 \%$ of male respondents have reported that they often get beatings by the teacher for the mistakes committed the other hand $20 \%$ of respondents are getting punishments without any mistakes and it is very less in female as $14 \% .70 \%$ of males and $68 \%$ of female have reported that most of the time they experience scolding by their teachers. $40 \%$ of male and $14 \%$ of female respondents are feeling uncomfortable to express their feelings to the teachers. $66 \%$ of male and $78 \%$ of female respondent are ready to accept the guidance given by teachers.

Scholastic backwardness: in total samples $38 \%$ of male and $22 \%$ of female respondents are scholastically backwards, repetitive negative academic performance. $72 \%$ male respondents are medium and $28 \%$ are very good in their academic. $44 \%$ of female respondents are medium and $56 \%$ are very good in their academic achievement. 30\% of male respondents responded that they are demotivated and $12 \%$ of females are also demotivated by continues academic pressure from their teachers. $32 \%$ of male respondents are very serious about their academic future and $68 \%$ are not so serious. $28 \%$ of female respondents reported they are also serious about their academic future and $72 \%$ are not.

\section{RECOMMENDATIONS AND SUGGESTIONS :}

The children with several behavioural problems in the school are not given importance to understand the real cause behind their problems. There is a concept in the schools that negative approaches are the best methods to control the children; so frequently the same methods are used to approach the child which is again and again damaging the psycho-social wellbeing of the children in the school 
[14]. About $70 \%$ of the population has reported that they are often facing emotional problems by the negative approach of the teachers. It is recommended that to create awareness among teachers in the school for the smooth handling the children with the positive approaches. Different programs must be planned to strengthen the children's capacity to cope with challenges and to make them emotionally strong [5], [22]. A flexible environment in the school must be created to make the child develop academically and socially.

\section{REFERENCES :}

[1] Grayson, J. (2006). Corporal punishment in schools. Virginia Child Protection Newsletter, 76, 1216.

[2] Willms, J. D, Somers M. A. (2001). Family Classroom and School Effects on Children's Educational Outcomes. International journal of School Effectiveness and Improvement, 12(4), 409-445.

[3] Annette M., La Greca, and Hannah Moore Harrison, (2005). Adolescent Peer Relations, Friendships, and Romantic Relationships: Do They Predict Social Anxiety and Depression?. Journal of Clinical Child and Adolescent Psychology, 34(1), 49-61. DOI: https://doi.org/10.1207/s15374424jccp3401_5.

[4] Yousef Mehdipour, \& D. Balaramulu, (2013). Students attitude toward teacher's behaviour in Hyderabad Universities. International journal of scientific and research publications, 3(6), 1-5.

[5] Desimone, L. M. (2009). Improving impact studies of teachers' professional development: Toward better conceptualizations and measures. Educational researcher, 38 (3), 181-199. DOI: https://doi.org/10.3102/0013189X08331140.

[6] Seventh all India School Education Survey- NCERT,(2002).National Council Of Educational Research And Training DOI: http://www.ncert.nic.in/programmes/education_survey/pdfs/schools_physical_ancillary_facilitie s.pdf.

[7] Ministry of Home Affairs, (2016). Crime in India.National Crime Records Bureau, New Delhi.

[8] Finn, J. D., \& Rock, D. A. (1997). Academic success among students at risk for school failure. Journal of applied psychology, 82(2), 221. DOI: http://dx.doi.org/10.1037/0021-9010.82.2.221.

[9] Gururaj, G. Gouda, D’Mello Laveena, (2018). Introducing “Cap Concept” in a Class Room Learning for the Students to Achieve Success. "Exploring Avenues in Banking, Management, It, Education \& Social Sciences”, ISBN No.: 978-93-5321-508-8, 179- 185.

[10] Lane, K. L., Wehby, J. H., \& Cooley, C. (2006). Teacher expectations of students' classroom behaviour across the grade span: Which social skills are necessary for success?. Exceptional Children, 72(2), 153-167. DOI: https://doi.org/10.1177/001440290607200202.

[11] Fhkps, B. (2013). Student classroom misbehaviour: An exploratory study based on teachers' perceptions. International journal of child health and human development, 6(1), 49-58.

[12] D’Mello, Laveena, Monterio Meena. \& Pinto, Nelson (2018). The quality of work life and job satisfaction of private sector employees. International Journal of Management, Technology and Social Sciences (IJMTS), 3(1), 11-17. DOI: http://doi.org/10.5281/zenodo.1156175.

[13] Straus, M. A. (1991). Discipline and deviance: Physical punishment of children and violence and other crime in adulthood. Social problems, 38(2), 133-154. DOI: https://doi.org/10.2307/800524.

[14] Committee on School Health, (2000). Corporal punishment in schools. Pediatrics, 106(2), 343343. DOI: http://pediatrics.aappublications.org/content/106/2/343.

[15] Greydanus, D. E., Pratt, H. D., Spates, C. R., Blake-Dreher, A. E., Greydanus-Gearhart, M. A., \& Patel, D. R. (2003). Corporal punishment in schools: Position paper of the Society for Adolescent Medicine. Journal of adolescent Health, 32(5), 385-393. 
[16] Smith, P. K., Mahdavi, J., Carvalho, M., Fisher, S., Russell, S., \& Tippett, N. (2008). Cyberbullying: Its nature and impact in secondary school pupils. Journal of child psychology and psychiatry, 49(4), 376-385. DOI: https://doi.org/10.1111/j.1469-7610.2007.01846.x.

[17] Robert, A. Baron, Girishwar Misra, (2016). Psychology Indian Subcontinent Edition.Pearson India Education Service Pvt. Ltd, New Delhi.

[18] Aithal, P. S. \& Suresh Kumar, P. M. (2018). Approach to Confidence Building as a Primary Objective in Post Graduate Degree Programmes. International Journal of Applied engineering \& Management Letters (IJAEML), 2(1), 64-71. DOI: http:// doi.org/10.5281/zenodo.1205185.

19] Ferris, D. R. (1997). The influence of teacher commentary on student revision. Tesol Quarterly, 31(2), 315-339. DOI: https://doi.org/10.2307/3588049.

[20] Daley, D. \& Birchwood, J. (2010). ADHD and academic performance: why does ADHD impact on academic performance and what can be done to support ADHD children in the classroom?. Child: care, health and development, 36(4), 455-464. DOI: https://doi.org/10.1111/j.13652214.2009.01046.x.

[21] Giallo, R., \& Little, E. (2003). Classroom behaviour problems: The relationship between preparedness, classroom experiences, and self-efficacy in graduate and student teachers. Australian Journal of Educational \& Developmental Psychology, 3(1), 21-34.

[22] Ramesh, B. G. (2013). Vidyarthigalalli Vattada. Sapna Book House Pvt. Ltd., Bangalore.

[23] Haidet, P., \& Stein, H. F. (2006). The role of the student-teacher relationship in the formation of physicians.Journal of General Internal Medicine, 21(1), 16-20.

[24] Ainscow, M., \& Sandill, A. (2010). Developing inclusive education systems: the role of organisational cultures and leadership. International Journal of Inclusive Education, 14 (4), 401416. DOI: https://doi.org/10.1080/13603110802504903.

[25] Vello Hein, (2012). The effect of teacher behaviour on students motivation and learning outcomes. A review. 18, 9-19. DOI: https://doi.org/10.12697/akut.2012.18.02.

[26] Ogunshola, F, \& Adewale A. M. (2012). Effects of Parental Socio-Economic Status on Academic Performance of Students. International journal of Academic Research in Business and Social Science, 2(7), 230.

[27] Caro, D. H. (2009). Socio-economic status and academic achievement trajectories from childhood to adolescence. Canadian Journal of Education, 32(3), 558-590.

[28] Aithal, P. S. \& Suresh Kumar, P. M. (2016). Teaching - Learning Process in Higher Education Institutions. International Journal of Multidisciplinary Research and Modern Education (IJMRME), 2(1), 662-676. DOI: http://doi.org/10.5281/zenodo.160956.

[29] Joseph Murphy, (2014). Psychic Perception. Manjul Publishing House Pvt. Ltd, New Delhi.

[30] Aithal, P. S. \& Suresh Kumar, P. M. (2016). Student Evaluation and Reforms in Higher Education Institutions. International Journal of Multidisciplinary Research and Modern Education (IJMRME), 2(1), 652-661. DOI: http://doi.org/10.5281/zenodo.160932. 